\title{
Polymorphic Form Determination
}

National Cancer Institute

\section{Source}

National Cancer Institute. Polymorphic Form Determination. NCI Thesaurus. Code C134269.

Tests to determine the crystalline form of a particular solid material. 